\title{
Heritage education experience supported in augmented reality
}

\author{
Experiencia de educación patrimonial apoyada en realidad aumentada
}

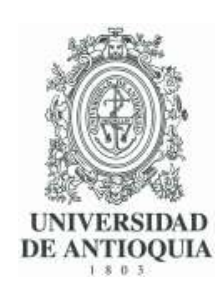

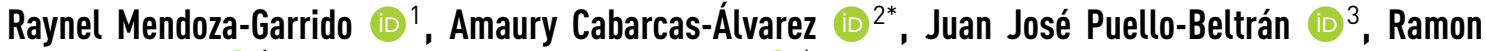 \\ Fabregat-Gesa (101', Silvia Margarita Baldiris-Navarro (104 ${ }^{4}$ \\ ${ }^{1}$ Instituto de Informática y Aplicaciones, Universitat de Girona. Plaça de Sant Domènec, 3. C.P. 17004. Girona, España. \\ ${ }^{2}$ Facultad de Ingeniería, Universidad de Cartagena. Calle 30 \# 48-152. C.P. 130015. Cartagena, Colombia. \\ ${ }^{3}$ Facultad de Ingeniería, Universidad del Sinu. Transversal 54 \# 41-117. C.P. 130014. Cartagena, Colombia. \\ ${ }^{4}$ Universidad Internacional de la Rioja. Av. de la Paz, 137. C.P. 26006. La Rioja, España.
}

\section{CITE THIS ARTICLE AS:}

R. Mendoza, A. Cabarcas, J. J. Puello, R. Fabregat and S. M.

Baldiris. "Heritage education experience supported in augmented reality", Revista Facultad de Ingeniería Universidad de Antioquia, no. 99, pp. 52-62, Apr-Jun 2021. [Online]. Available: https: //www.doi.org/10.17533/ udea.redin. 20200582

\section{ARTICLE INFO:}

Received: October 21, 2019 Accepted: June 01, 2020

Available online: June 01, 2020

\section{KEYWORDS:}

Heritage education; framework for heritage education; augmented reality

Educación patrimonial; framework para educación patrimonial; realidad aumentada
ABSTRACT: Heritage Education is a process that traditionally takes place within the classroom, where the teacher transmits some knowledge to the student; however, new ways have been implemented to develop Heritage Education processes supported by different technologies where Augmented Reality is included. This paper describes the process of implementing the "Framework for Heritage Education supported by Augmented Reality", which proposes guidelines for the development of technology solutions based on Augmented Reality in the context of Heritage Education, through the deployment of an application called "Social Heritage "developed under the guidelines of this Framework. The paper describes the implementation process of the Framework in the city of Cartagena - Colombia and the validation process with the end users. For the evaluation of the experience, the motivation test was used for the instructional design that measures the categories: Attention, Relevance, Confidence and Satisfaction. This test was applied to a group of students and a group of tourists. The validation results show that the use of augmented reality motivated both students and tourists in the development of heritage education processes. This allowed us to conclude that augmented reality technology is pertinent when promoting learning processes in the context of heritage.

RESUMEN: La educación patrimonial es un proceso que tradicionalmente se desarrolla dentro del aula de clase, en donde el docente trasmite al estudiante unos conocimientos, sin embargo últimamente se han implementado nuevas formas para desarrollar procesos de educación patrimonial apoyados en distintas tecnologías donde se incluye la Realidad Aumentada. Este articulo describe el proceso de implementación del "Framework para la Educación Patrimonial apoyado en Realidad Aumentada", que propone lineamientos para el desarrollo de soluciones tecnologías basadas en Realidad Aumentada en el contexto de la Educación Patrimonial, mediante el despliegue de un aplicación llamada "Social Heritage" desarrollada bajo los lineamientos de este Framework. El artículo describe el proceso de implementación del Framework en la ciudad de Cartagena - Colombia y el proceso de validación con los usuarios finales. Para la evaluación de la experiencia, se utilizó la prueba de motivación para el diseño instruccional que mide las categorías: Atención, Relevancia, Confianza y Satisfacción. Esta prueba se aplicó a un grupo de estudiantes y un grupo de turistas. Los resultados de la validación muestran que el uso de la realidad aumentada motivó tanto a estudiantes como a turistas en el desarrollo de procesos de educación patrimonial. Lo cual permitió concluir que la tecnología de realidad aumentada es pertinente a la hora de promover procesos de aprendizaje en el contexto del patrimonio.
* Corresponding author: Amaury Cabarcas Álvarez

E-mail: acabarcasadunicartagena.edu.co

ISSN 0120-6230

e-ISSN 2422-2844

\section{Introduction}

Heritage Education is any process that enables people to understand and appropriate their tangible and intangible 
heritage [1]. In the school environment, teachers use heritage education to transmit knowledge to the students. There are different approaches related to Heritage Education, Fontal and Marin propose one of them and identify the following elements [2]:

- Context (the place where the process of Heritage Education is developed).

- Content lthe educational resources to develop the methods of Heritage Education).

- Teacher (who plays the role of the teacher).

- Learner (student).

The present work focuses on the relationship between learner, context, and content. The learner is anyone who wants to develop a process of Heritage Education. The context refers to the real environment, and the content is used to support the application of Heritage Education, accessed with Augmented Reality (AR) technology. AR technology allows superimposing content in the real world using a device [3], and people can have access to interactive content that works like support for on-site Heritage Education tours. AR technology is an essential support for educational processes since there have already been advances that show its efficiency [4]. One of the fields of application of this technology is heritage education since it allows for the design of interactive experiences between people and heritage [5]. The AR improves the process of Heritage Education in a real context. About Heritage Education, Augmented Reality has been tested through the development of diverse types of applications in different circumstances, including education, exhibitions, exploration, reconstruction, and virtual museums, improving the user experience and access to knowledge [6].

On the other hand, Bacca et al. [4] develop a systematic review of the literature analyzing 30 works. These systematic reviews investigate the incidence of educational processes mediated by $A R$, and the progress of $A R$ in the educational context. It also enumerated the advantages of $A R$ in educational processes, among which the increase in learning, motivation, interaction, and collaboration stand out. The study makes it possible to affirm that augmented reality is an ideal technology for the development of heritage education processes in the real context.

Given the above consideration, we developed a "Framework to Heritage Education supported in Augmented Reality," this framework proposes guidelines for developers, content creators, and entities in charge of heritage, to implement technologies and actions to perform heritage education processes supported by Augmented Reality [7].
Another essential aspect of the structure of the Framework is the proposed method of collaborative management. This method allows any person who is part of the heritage education process to be the creator of the contents. However, in this method, there is an actor called Patrimonial Manager who is an expert in the heritage of a particular site; this actor validates content complies with the guidelines to use in the process of Heritage Education supported by augmented reality. For the definition of the method, using the concepts of the co-design of contents according to the following authors:

'Co-design approaches where the end-users' voices heard from the beginning of the ideation process by integrating them into multidisciplinary teams" [8] are essential opportunities in educational settings to improve learning scenarios allowing all stakeholders to be part of the creation of learning experiences equally.

Co-design, according to [9], represents for learning: a "highly-facilitated, team-based process in which teachers, researchers, and developers work together in defined roles to design an educational innovation, realize the design in one or more prototypes, and evaluate each prototype's significance for addressing a concrete educational need."

Co-design principles promote the richness of expression and encourage all kinds of participants to externalize their ideas [10]. While a "need and market potential for conceiving and proposing specific Virtual Learning Environment (VLE) platforms that foster e-learning uptake within the cultural heritage educational sector" has been identified already [11], content design for heritage education can benefit especially by the co-design. These happen because of the enrichment that comes from the articulation of different knowledge of specialized actors that can contribute to the content creation. The actors can be, Heritage Experts, History Experts, Tourism Experts, Social Science Experts, among others. The participation of the citizens or visitors could enrich the content creation with real experiences, particularly interesting for the content consumer.

There are several approaches developed aiming to facilitate the co-design of Heritage Content supporting the appropriation of heritage by different people. One of these is "CoDICE," a software tool aimed at helping various teams in the co-design of digital encounters with cultural heritage." CoDICE does not deal with the content creation process itself, but provides a platform to share different ideas and outcomes to help each participant, including end-users [10]. 


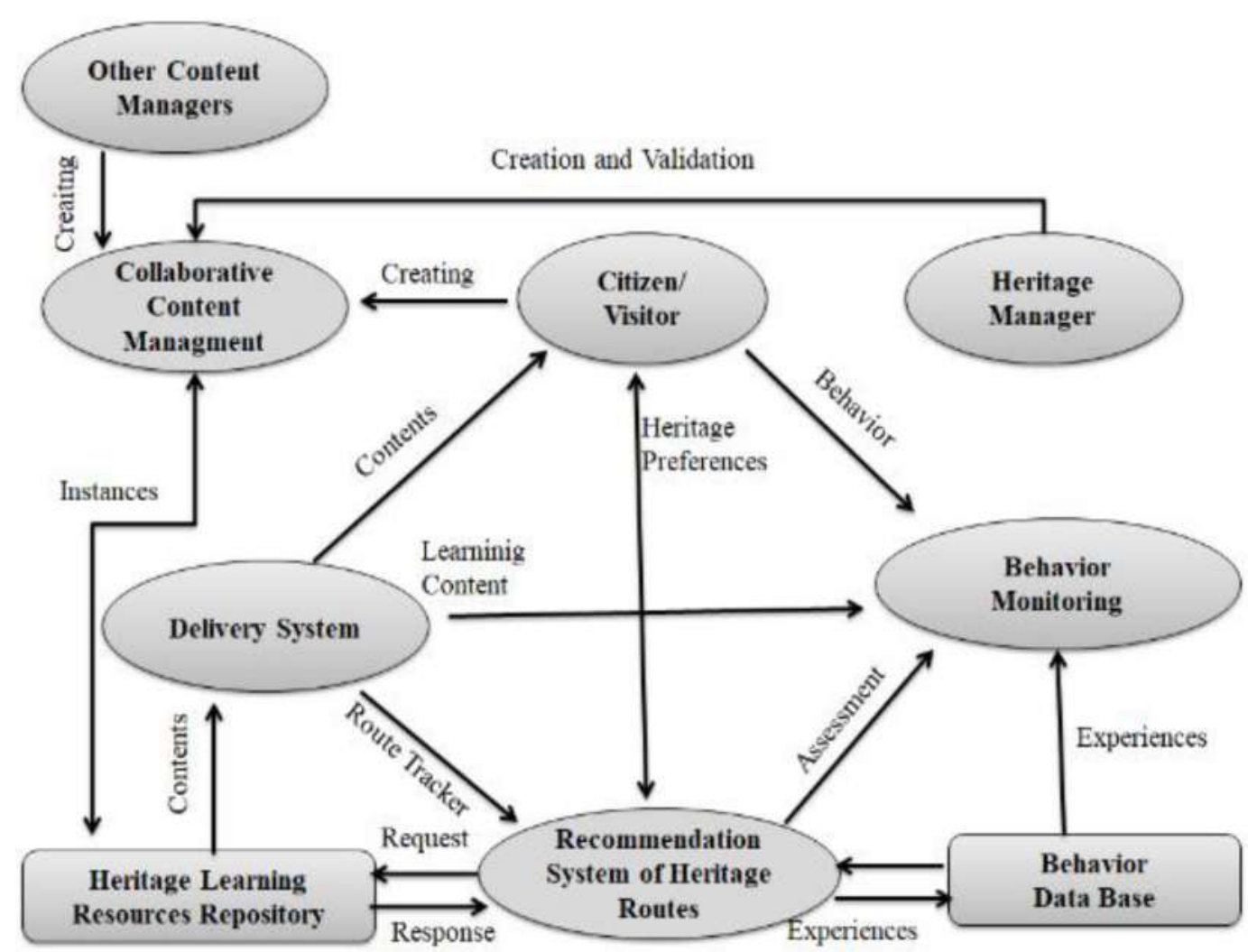

Figure 1 The framework to Heritage Education supported in AR

The framework used in this paper was implemented in Cartagena de Indias (Colombia), a city recognized by UNESCO as historical and cultural heritage of humanity. During this implementation, all the processes defined by the framework performed in an application based on Augmented Reality called "Social Heritage" [12]. The validation process uses two user groups; the first one refers to a group of high school students from the Promoción Social school who has a deepening emphasis on tourism. The second group was a group of citizens and visitors who were developing tourist activities in the historic center of Cartagena. To perform the validation of "Framework to Heritage Education supported in Augmented Reality," a motivation is used, which refers to a human dimension that explains why people make an effort to reach an objective and why people work actively to achieve that objective. For the study, the ARTS model (Attention, Relevance, Trust, and Satisfaction) was used [13]. This paper has the following sections: first it presents the description of the framework for heritage education supported in augmented reality. Then, it contains the explanation of the method of collaborative content management. It is followed by the application of Social Heritage and the methodological definition of the validation study, then the results, and the last section presents the conclusions and future work.

\section{Framework for heritage education supported in augmented reality}

The proposed framework is based on the LTSA architecture [14] developed by the Learning Technology Standards Committee - LTSC [15]. It introduces a neutral architecture for the learning, education, and training processes supported by information technologies. In this case, the elements were changed and adapted to the context of Heritage Education. The participants involved in the framework are the following: 1) Citizen/Visitor, who refers to anyone who carries out the process of Heritage Education. 2) Heritage Manager, who is the expert in the heritage of a particular place, and is also responsible for evaluating the quality of the content. 3) Other Content Managers, anyone who has the knowledge and participates in the content creation process. Figure 1 shows the structure of the Framework [7]. The Framework to Heritage Education supported in Augmented Reality is composed of the following components:

The proposed "Framework for Heritage Education supported by Augmented Reality," the apprentice is the citizen or visitor who is interested in developing a process of Heritage Education. The term citizen refers to the person born or who lives in a specific place. The 


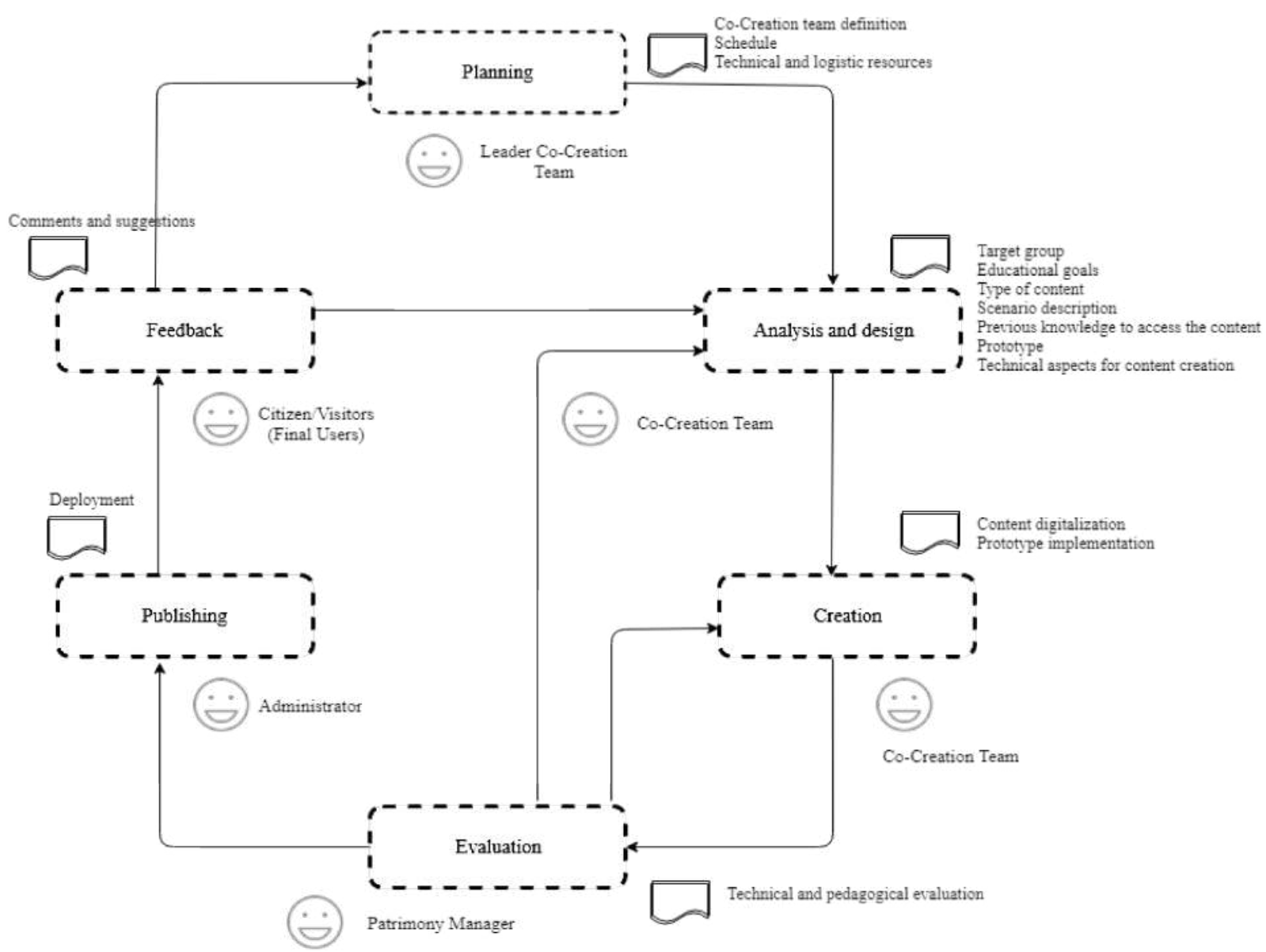

Figure 2 Content management method

term visitor refers to the person who is temporarily in a particular location. A visitor can be a national or a foreigner.

The evaluation process observes and values the apprentice's behavior on the diverse heritage that he has traveled, consulted, or valued. The visited heritage locations are those that the person transits or observes. The consulted heritage locations are those of which the person has requested extended information. Finally, the valued heritage locations are those that the person has qualified according to their experience in the learning process. Then all people's behavior is stored in a behavior repository. The behavior repository feeds the "User Model" and the "Context Model" that are used to recommend heritage learning routes to citizens or visitors.

In the same way, a "Method of Recommendation of Heritage Learning Routes" is defined and aims to propose personal visits to citizens (citizens or visitors) based on the information stored in their "User Model" and in the "Model of the Context." Initially, the recommendation process based on the declaration made by the citizen or visitors of their interests. This recommendation method becomes a fundamental process within the Framework as it proposes elements for people to generate learning experiences based on their interests. The delivery system is based on Augmented Reality technology and is responsible for deploying the increased content to citizens or visitors in different formats: audio, videos, text, animations. These contents are available for different types of devices, such as phones, glasses, and tablets.

On the other hand, heritage content is stored in the form of learning resources, constituting an extensive repository of heritage learning objects. Such objects can be visualized using Augmented Reality, which, as mentioned above, allows combining or complementing real-world objects with virtual objects or information superimposed on the real world. As a result, in these systems, virtual objects seem to coexist in the same space with the real world. This technology allows the situation and contextualization of the learning experience of citizens and visitors by developing the process of Heritage Education in real scenarios and based on the model of Educational Heritage education lcitizens and 


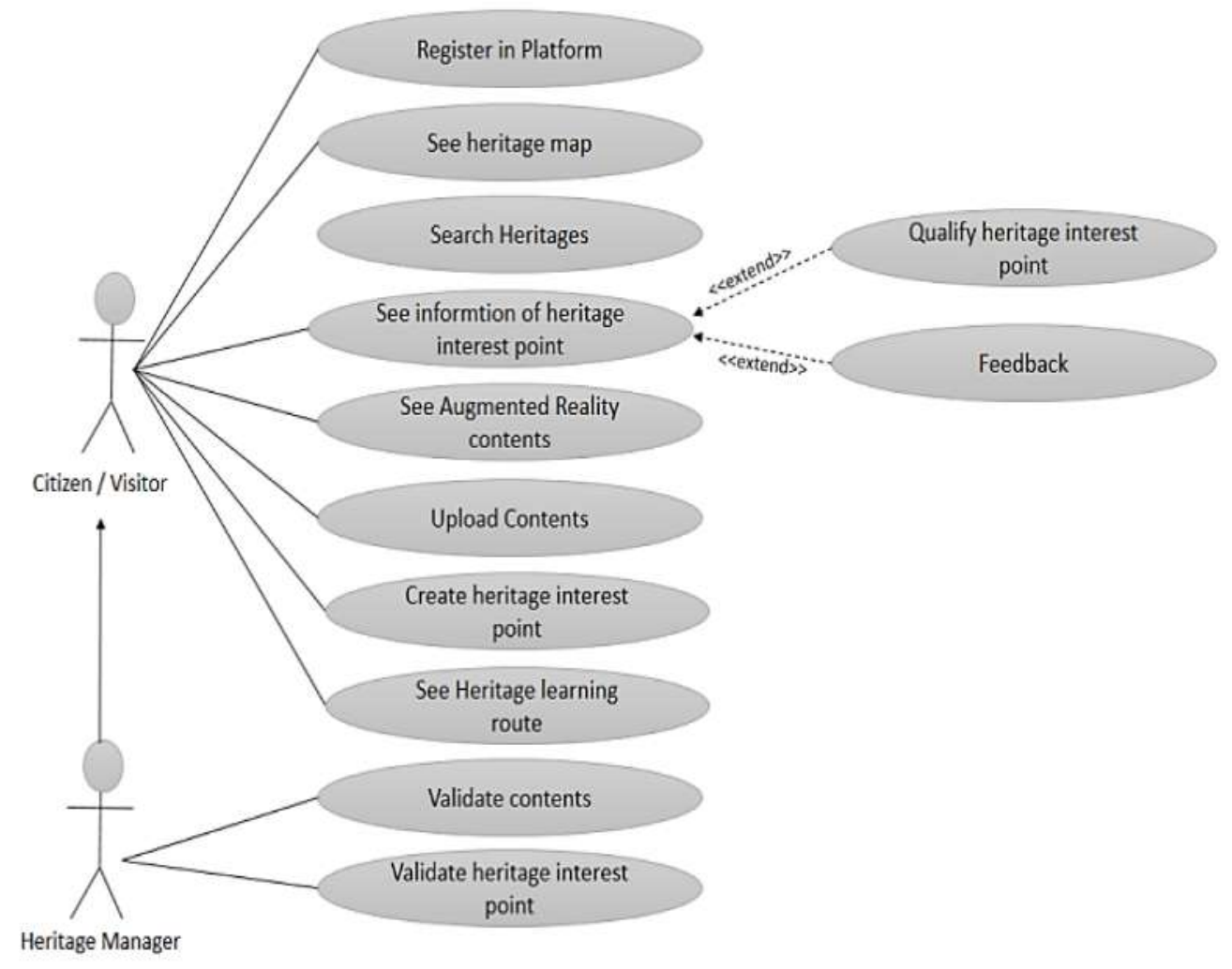

Figure 3 Use case diagram

visitors), context (specific place), and content (increased content). A key element to highlight in the "Framework for Heritage Education supported by Augmented Reality" is the definition of the "Method of collaborative management of Heritage Content." The method based on the fact that learning objects for a process of Heritage Education are created from the collaborative way by the various actors involved.

The inclusion of the entity called Patrimonial Manager, which represents the people and institutions responsible for education, dissemination, and asset management in a particular site, stands out. This entity is responsible for the specification of requirements and the process of validation of heritage learning objects. The validation of these contents guarantees that the objects created are suitable to support a process of Heritage Education. A central aspect as a result of the implementation corresponds to the definition of the Heritage Map of the particular site. This Patrimonial Map corresponds to the set of Heritage Points of Interest of a specific place.

\subsection{Method of collaborative content management}

The "Collaborative Content Management Method" is of great importance within the Framework for
Heritage Education supported by Augmented Reality as it guarantees that the contents are useful for the development of the Heritage Education process. Previously, the actors of the Framework presented in a general way a complete extension of the actions and roles that each one of the Collaborative Content Management Method performs:

- Citizen/Visitor: Any person who carries out the process of Heritage Education. In this sense, any citizen or visitor can propose content that is useful for other people.

- Patrimonial Manager: The person who is an expert in the heritage of a particular place and who also has knowledge of teaching methods for Patrimonial Education. This role can create content for a specific location. It must also validate the quality of the content of the other authors, ensuring that the material responds to the learning objectives.

- Administrator: is the person in charge of managing the platform that supports the process of Heritage Education, where the contents are stored, and the process of heritage education developed.

- Other Content Managers: anyone who has the knowledge and participates in the creation of content, by example, graphic designers, software developers. 
The people who play these roles constitute the content creation team, that is, the group of people involved in the content creation process. Figure 2 shows the definition of the collaborative content management method.

Figure 2 shows the phases of the process of collaborative content management. The first phase is planning: This phase defines the content creation team (citizens, visitors, or other content creators), enlisted the schedule, and the technical and logistic resources for the co-creation process. The second one is analysis and design: In this phase, the content creation team determines what the content is being created for or selects a content learning objective defined for a Patrimonial Interest Point. As mentioned, Augmented Reality technology allows the creation of interactive learning experiences between end-users (citizens/visitors) and Heritage Points of Interest. These users can access in real-time the available contents of each Patrimonial Interest Point. Here is where the importance of defining good content lies, which, in addition to responding to the educational objective, must be easily accessible from a technical point of view and supported by the devices of each user. The third phase is creation: In this phase, the team creates all the contents. Each of the characteristics defined in the Analysis and Design phase taken as the basis. The result of this phase is the content itself. It emphasizes that the actors involved in this phase can be anyone who wishes to create content for Heritage Education. In this phase, it implements the digital content and the prototype. The creation phase is carried out by the content co-creation team. The fourth phase is evaluation and validation:

The Patrimony Manager actor validates the quality of the contents taking into account that the created material complies with the proposed learning objectives. The following aspects should be considered in the evaluation process:

- Fulfillment of learning objectives: Evaluated whether the content created meets the learning objective.

- Compliance with the target audience: Evaluated whether the content created complies with the elements delivered to the target audience proposed.

- Technical aspects of the content: Evaluated the content quality from the technical perspective, i.e., image quality, audio quality, video quality.

- The result of the evaluation may lead to any of the following actions:

- That the content could be returned to the analysis and design phase if it does not meet the learning objectives or the target audience proposed.
- That the content could be returned to the creation phase if there is any technical deficiency in the created content.

- The content passes to the publication phase.

Publishing: In this phase, the content already validated is published in the Patrimonial Interest Point. These contents may be visualized by the different actors that carry out the Heritage Education process. The administrator of the Heritage Education platform, supported by AR, makes the publication once the contents are evaluated and validated. After the evaluation and validation phase, then the publication phase continues: the "Heritage Learning Resource Repository" stored the published contents, then the apps "Social Heritage" accessed these materials. The last phase is feedback and collaboration: In this stage, the Citizens / Visitors access the content created and make comments and observations related to these contents. Co-creators can use these comments to improve published material, or other people can create their content to enhance the process of Heritage Education. The feedback given by the users allows the co-creation team to improve the materials, which can result in the planning, analysis, and design process.

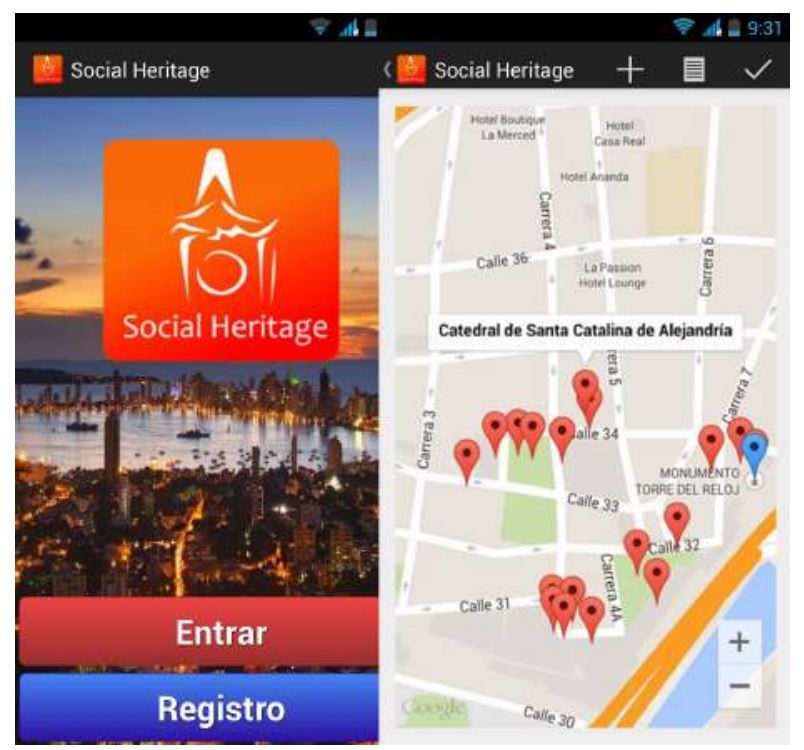

Figure 4 Social heritage application

\subsection{Social heritage - Augmented reality application}

The application was developed using the parameters established in the framework described in the previous section. The app was developed for two categories of users. The first is the Citizens/Visitors, who use the platform to create the processes of Heritage Education. The second category refers to Heritage Managers who, 
as previously mentioned, thanks to their experience and knowledge about heritage, have the fundamental responsibility of validating that the contents and points of heritage interest comply with the requirements for developing Heritage Education processes. Figure 3 presents the use case diagram.

Features of the Social Heritage application: The application begins with a login or registration process. This registration allows capturing the data and preferences of the users. Once logged in, users have different options that compose the main menu and with which they can interact: visualization of points of interest through the geographic information system, personalized search through lists, loading contents, evaluation of contents, and heritage points and viewing of information points with Augmented Reality. Figure 4 presents Social Heritage applicaction.

Technical aspects of the application: programming language using was JAVA. The development environment was the Eclipse IDE, which supports the Android SDK. For the development of the geographic information system, Google Play Services was used to generate a map with markers that represent the points of heritage interest and trace the indications that mark the heritage route. For the Augmented Reality component, Metaio SDK was used, which provides libraries for the creation of superimposed radars on screen and their visualization through Augmented Reality. Figure 5 shows the architecture of the application.

Application Deployment: The process, including a group of people conformed by students and professionals from different areas. The contents used corresponds to the city of Cartagena. The co-creation team was made up of six people, and the wealth manager was an expert teacher in heritage education in the city of Cartagena. The application shows 86 points of heritage interest in the historic center of the city of Cartagena.

\section{Validation Study}

The object of the study developed was to analyze, if the use of the Social Heritage application, motivated the end-users (Citizens and Visitors) to carry out their Heritage Education process. In this case, motivation is understood in terms defined by [16] and generally defined as what explains the direction and magnitude of a person's behavior, or in other words, explains what objectives people choose to follow and with what intensity they pursue them. For the validation, the study used the ARCS model (Attention, Relevance, Confidence, and Satisfaction) introduced by [17]. The studies carried out by [18-21] validate the application of the Instructional Design
Motivation Instrument (IMMS).

The study was defined as a descriptive and quantitative study. For the development of the validation, the Patrimonial Interest Points located in the historic center of the city of Cartagena were used as a scenario. The Social application was used as an Augmented Reality platform for Heritage Education. The validation study implemented two groups described below: The first group is made up of a group of 36 students (21 women and 15 men) from the 10th grade of high school, the Social Promotion Educational Institution with ages between 14 and 16 years. The group is part of the studies of the Technical Media in Promoter of National Tourist Services of the mentioned institution. The social stratum where most of these students come from is 1 and 2 (which corresponds to people with limited financial resources). According to data taken before the validation process, 30\% do not have a mobile phone, and of those with a mobile phone, about $85 \%$ do not have data plans and using their home or school Wi-Fi. They also indicate that this team uses it mostly to access social networks and little to develop academic activities. The selection of these students is justified taking into account that these students are being trained as future tourism promoters, and having access to this type of technology allows them to open the horizon to better job opportunities. The second group was made up of Citizens/Visitors of Cartagena, Colombia. These people were randomly selected and among people who were in the historic center of the city of Cartagena, where most of the Patrimonial Points of Interest of the city are located, at the time of validation. The sample considered people over 14 years old.). The sample size was estimated through the Equation 1 proposed in [22].

$$
n=\frac{z_{\frac{\alpha}{2}}^{2} s^{2}}{e^{2}}
$$

Where $Z_{\alpha / 2}^{2}$ corresponds to the precision that researchers hope to have in the study, considering a confidence interval. The strut value located in the probability distribution table of the normal distribution. $S^{2}$ corresponds to the population variance, which in the case of estimation of proportions in large populations corresponds to $p(1-p)$, e refers to the error tolerable for the investigator. In this case, a $95 \%$ confidence interval and a margin of error of 0.07 an extensive. The population proportion $p$ found was the corresponding proportion of people who reported having had successful experiences in their heritage education process, which was 0.76. Given the specifications, Equation 2 shows the formula applied to calculate the sample size:

$$
n=\frac{1.96^{2} *(0,76)(0,24)}{0.07^{2}}=143
$$




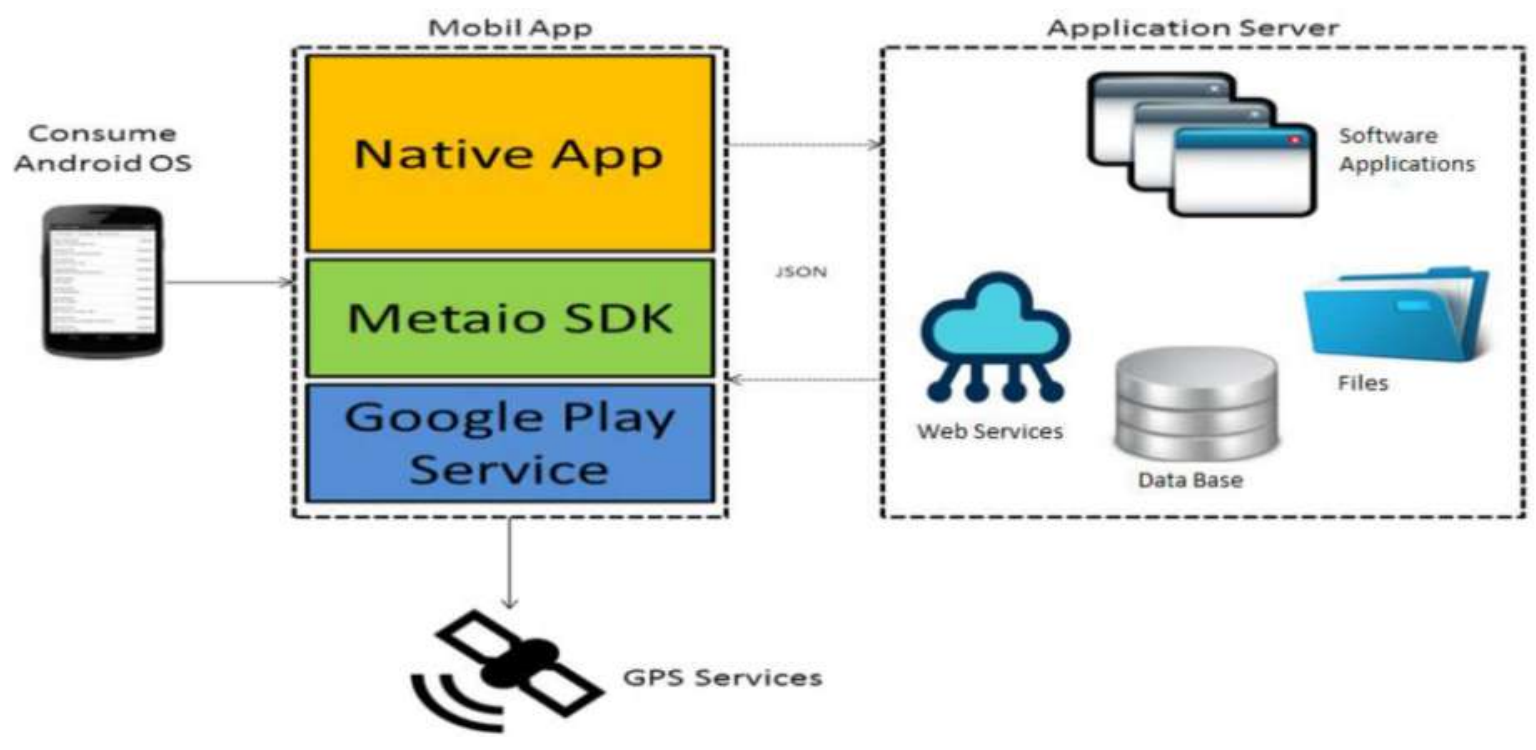

Figure 5 Application architecture diagram

For this reason, 143 individuals were selected and no corrections were made for finitude since the population size was not known precisely. The sample was made up of 67 women and 76 men, the average age was 34 years old, and the standard deviation for age was 8.86. The information was collected using a survey applied to the participants. For this, the ARCS model (Attention, Relevance, Confidence, and Satisfaction) defined as a conceptual basis, and the Instructional Design Motivation Instrument (IMMS) is used [23]. The IMMS instrument measures four dimensions for motivation that give the model its name. The survey contains 29 questions, and its rating range corresponds to a Likert scale of 1 to 5 . For the author, attention refers to maintaining curiosity and interest. Relevance refers to connecting the needs, interests, and motivations of students. The Trust focuses on maintaining a positive expectation of the process, and satisfaction refers to the enjoyment of the experience, whether through internal feelings or external recognition. On the other hand, the instrument used for citizens and visitors (Group 2) considered a subset of 8 questions (2 for each dimension) of IMMS instead of 29 due to the short time available for participants to complete the instrument. An interdisciplinary group that worked on this study formed by psychologists, pedagogues, and technical experts, selected these questions.

The validation process consists of the five phases detailed below: Phase 1: Explanation: In this phase, the different actors have explained their role in the validation process and its objectives. The participants of Group 1 (Students) were taught in a classroom the validation study and motivated for the educational experience. This phase has a duration of 45 minutes. For those of Group
2 (Citizens / Visitors), the explanation was made to each person individually when they approached at the validation site. On average, this explanation took 2 minutes.

Phase 2: Content co-creation: included the development of a co-creation process with two teams. The co-creation team 1 included students from the Normal Superior School of Cartagena. The students in this group had little or almost no experience in content creation. The group consisted of 30 students, of which $40 \%$ were men and $60 \%$ women; the average age was 16 years. The Co-Creation Team 2 included a co-creation team of 3 people, all of the Systems Engineering studentss from the Technological Foundation of the Comfenalco University - Cartagena. These participants had previous experience in creating educational content.

Phase 3: Recognition and Iteration with contents and Augmented Reality platform: This phase consisted of the Heritage Education process supported by the Social Heritage application with the created materials published in the app 115 contents of Team 1 co-creation and 6 of Team 2 co-creation). Participants used Augmented Reality and accessed the contents during the tour of the Points of Patrimonial Interest in the historic center of the city of Cartagena. The student group traveled at least 8 Patrimonial Interest Points on average, while the Citizens / Visitors, on average, traveled only 3 Patrimonial Interest Points. The average iteration time of the students was 1 hour, while the Citizens / Visitors group interacted with the contents for an average of 10 minutes.

Phase 4: Data collection: Group 1 (Students) used the test for full Motivation in Instructional Design Instrument 
[23], and for group 2, we proceed to collect the information through a questionnaire with a subset of 8 questions from the same test.

Phase 5: Evaluation (Group 1 only): For the evaluation with the students (Group 1), an educational activity called "Knowledge meeting" was created, which consists of the students making a presentation highlighting the main aspects of each of the Patrimonial Interest Points visited and based on questions from the teacher, the experience is shared with the rest of the classmates. Phase 6 : Descriptive analysis: This phase consists of the study of the information for each of the groups. Then, it shows the results according to the elements provided in the instrument and the different categories. This analysis aims to determine if the use of the contents and the Social Heritage application motivated the participants to develop the processes of Heritage Education.

\section{Results}

Concerning the Method of Co-creation of Patrimonial Contents, the process of collaborative creation of patrimonial contents was developed in the evaluation scenario even though $30 \%$ of the co-creation Team 1 members had no prior technical knowledge. As a result of this phase, 15 assets were created, all of them validated by the Property Manager and subsequently published by the administrator in the Social Heritage application. For its part, the Co-creation 2 team allowed the creation of 6 heritage contents.

The process of creation of heritage content carried out by people with little or almost no experience (Team 1 of co-creation) required more accompaniment than what was done with the creators with experience (Team 2 of co-creation). In the first case, it was necessary to carry out a training process, mainly in technical aspects.

On the other hand, for the phase of use of the application, the following results were obtained. With Group 1 (Students) and with Group 2 (Citizens/Visitors) shown below. Group 1 Result (Students). Table 1 shows the results obtained by the group of students for each of Keller's motivation categories.

Table 1 Student group motivational test results

\begin{tabular}{llll}
\hline Category & Average & Deviation & $\begin{array}{l}\text { Variation } \\
\text { coefficient }\end{array}$ \\
\hline Attention & 4.2 & 0.8220 & $19.48 \%$ \\
Relevance & 4.0 & 0.9939 & $24.81 \%$ \\
Trust & 4.1 & 1.0461 & $25.38 \%$ \\
Satisfaction & 4.1 & 0.9873 & $23.94 \%$ \\
\hline
\end{tabular}

Taking into account the results of the Attention, Relevance, Confidence, and Satisfaction variables presented by their average, deviation, and coefficient of variation, it can be affirmed that the use of the contents and the Social Heritage application motivated the students to develop the Heritage Education process. However, aspects such as the number of images presented must be reviewed to generate greater user satisfaction. This evaluation was qualitative; the students shared their learning experience through the questions asked by the teacher. From the interventions, the teacher takes a grade. According to the data provided by the teacher of the 36 participating students, $83.3 \%$ of them had a good degree (between 4 and 5), 11.1\% obtained an acceptable degree (between 3 and 4 ), and $5.5 \%$ achieved an unsatisfactory degree (less than 3).

Table 2 shows the results obtained with group 2 (Citizens and Visitors), this table presents the average result for each of the eight questions selected by the group of experts from the IMMS instrument and that are associated with the four dimensions of motivation.

Taking into account the average, the deviation and the coefficient of variation of the results of the questions for the categories Trust, Satisfaction, Relevance, and Attention, it can be said that the use of the Social Heritage application and the contents motivated citizens and visitors the development of heritage education processes supported by Augmented Reality.

Table 3 shows the average by categories for Citizens / Visitors (Group 2). The four categories indicate that participants presented excellent Attention, Relevance, Confidence, and Satisfaction. In comparison with the results obtained by Group 1, it is observed that these Group 2 positive results were also obtained even when the time available for the use of the application and the contents were much shorter.

\subsection{Discussion of results}

In the validation study with the end-users, satisfactory results were obtained. About Group 1 (students), it can indicate that the results are excellent considering that the average rating of the dimensions, the standard deviation and the coefficient of variation, this would suggest that the contents and application of Augmented Reality motivated participants to develop an educational experience related to Heritage Education. These results could be corroborated by the observation.

On the other hand, the validation of Group 2 (Citizens / Visitors) showed that the motivation was right; this can corroborate, taking into account that the average 
Table 2 Citizens/visitors test result

\begin{tabular}{lllll}
\hline Question & Measurement & Average & Deviation & $\begin{array}{l}\text { Variation } \\
\text { coefficient }\end{array}$ \\
\hline $\begin{array}{l}\text { When I saw this exercise for the } \\
\text { first time, I had the impression } \\
\text { that it would be easy for me }\end{array}$ & Confidence & 4.0 & 0.9300 & $23.05 \%$ \\
\hline $\begin{array}{l}\text { While doing the exercise, I was } \\
\text { sure I could learn more about } \\
\text { this topic }\end{array}$ & Confidence & 4.5 & 0.7585 & $16.92 \%$ \\
\hline $\begin{array}{l}\text { Completing this exercise gave } \\
\text { me a sense of satisfaction }\end{array}$ & Satisfaction & 4.1 & 0.8949 & 21.69 \\
\hline $\begin{array}{l}\text { I enjoyed the development of } \\
\text { this exercise to learn }\end{array}$ & Satisfaction & 4.2 & 0.8045 & $18.99 \%$ \\
\hline $\begin{array}{l}\text { This exercise had aspects that } \\
\text { stimulated my curiosity }\end{array}$ & Attention & 4.3 & 0.7373 & $17.07 \%$ \\
\hline $\begin{array}{l}\text { The variety of images and } \\
\text { content helped me pay attention } \\
\text { and focus on the exercise }\end{array}$ & Attention & 4.0 & 1.0273 & $25.87 \%$ \\
\hline $\begin{array}{l}\text { Completing this exercise was } \\
\text { important to me. }\end{array}$ & Relevance & 4.2 & 0.8984 & $21.52 \%$ \\
\hline $\begin{array}{l}\text { It is clear to me that the content } \\
\text { of this exercise is related to } \\
\text { things I knew }\end{array}$ & Relevance & 4.1 & 0.8348 & $20.27 \%$ \\
\hline
\end{tabular}

Table 3 Average by category of citizens and visitors motivational

\begin{tabular}{llll}
\hline Category & Average & Deviation & $\begin{array}{l}\text { Variation } \\
\text { coefficient }\end{array}$ \\
\hline Confidence & 4.3 & 0.8763 & $20.58 \%$ \\
Relevance & 4.1 & 0.8661 & $20.89 \%$ \\
Attention & 4.1 & 0.9096 & $21.94 \%$ \\
Satisfaction & 4.2 & 0.8513 & $20.36 \%$ \\
\hline
\end{tabular}

results, the standard deviation, and the coefficient of variation. Besides, in their feedback, they asked when the Social Heritage application would be available for the city of Cartagena and expressed their interest in using it on future occasions. Regarding the categories, it can indicate that the participants of both groups presented a proper Attention, always showed sufficient interest and motivation for the development of the educational experience. Also, during the validation study, they showed excellent relevance. The Confidence category showed a positive expectation during the survey and concerning Satisfaction, and confirmed that users enjoyed the experience.

Likewise, it is essential to specify that a comparative analysis of Group 1 and Group 2 not made because their population is different, and their interests are significant, and also because the sample sizes are very different.

\section{Conclusions and future work}

Heritage Education has traditionally developed in school contexts, where the teacher imparts his knowledge to the students. However, it has demonstrated that the use of information technologies in the educational situation is helpful. Augmented Reality technologies, as a support process of Heritage Education, showed positive results, according to the results of the motivation study that has been developed, where participants have demonstrated a high degree of interest and motivation. The Augmented Reality supports positively, processes of heritage education in the real context. Besides, it is essential to measure motivation in final users; this allows improving the user experience in the context of education in general. Also, the heritage education processes is supported in augmented reality, as is the case of this article. This type of study improves the final product, focused on the interests of the final users. As a future work derived from this research, we have the implementation of the Framework to Heritage Education supported by Augmented Reality in another city that has a high tourist interest derived from its cultural and historical heritage legacy.

\section{Declaration of competing interest}

We declare that we have no significant competing interests including financial or non-financial, professional, or 
personal interests interfering with the full and objective presentation of the work described in this manuscript.

\section{Acknowledments}

A big thanks to the students of the Pedagogical Training group and the teacher Yolanda Barrios of the "Escuela Normal Superior". Additionally, to the teacher Modesta Barrios of the "Institución Educativa Promoción Social” for her support in the process of validation with the students and to the Comunicacions i Sistemes Distribuits project (MPCUdG2016) both from Universitat de Girona. Special thanks to the Open Co-creation project (TIN2014-53082-R) financed by Ministerio Español de Ciencia y Educación, and to the BCDS research group (GRCT40) which is part of the Comunicacions I Sistemes Intelligents - CSI consoled group (SGR-1469). The authors want to thank the "Universidad de Cartagena" for their contribution and support in the execution of this work.

\section{References}

[1] O. Fontal and A. Ibañez, "Estrategias e instrumentos para la educación patrimonial en españa," Educatio siglo XXI, vol. 33, no. 1, March 2015. [Online]. Available: https://doi.org/10.6018/j/222481

[2] 0. Fontal and S. Marín, "Approaches and models of heritage education in significant programs of oepe," EARI - Educacion Artistica Revista de Investigación, no. 2, pp. 91-96, 2011.

[3] R. T. Azuma, "Augmented reality: Approaches and technical challenges," in Fundamentals of Wearable Computers and Augmented Reality, W. Barfield and T. Caudell, Eds. New York, USA: CRC Press, 2001, pp. 27-63.

[4] J.Bacca, S. Baldiris, R. Fabregat, S. Graf, and D. Kinshuk, "Augmented reality trends in education: A systematic review of research and applications," Educational Technology \& Society, vol. 17, no. 4, pp. 133-149, Oct. 2014.

[5] Z. Noh, M. S. Sunar, and Z. Pan, "A review on augmented reality for virtual heritage system," in Learning by Playing. Game-based Education System Design and Development, Berlin, Germany, 2009, pp. 50-61.

[6] M. K. Bekele, R. Pierdicca, E. Frontoni, E. S. Malinverni, and J. Gain, "A survey of augmented, virtual, and mixed reality for cultural heritage," Journal on Computing and Cultural Heritage (JOCCH), vol. 11, no. 2, March 2018. [Online]. Available: https: //doi.org/10.1145/3145534

[7] R. Mendoza, S. Baldiris, and R. Fabregat, "Framework to heritage education using emerging technologies," Procedia Computer Science, vol. 75, 2015. [Online]. Available: https: //doi.org/10.1016/j.procs.2015.12.244
[8] J. Carroll, G. Chin, M. Beth, and D. C. Neale, "Development of cooperation: Five years of participatory design in the virtual school," in Proceedings of the Conference on Designing Interactive Systems: Processes, Practices, Methods, and Techniques (DIS 2000), New York, USA, 2000, pp. 239-251.

[9] J. Roschelle and W. Penuel, "Co-design of innovations with teachers: definition and dynamics," in ICLS 06: Proceedings of the $7^{\text {th }}$ international conference on Learning sciences, Bloomington, USA, 2006, pp. 606-612.

[10] P. Diaz, I. Aedo, and M. Vaart, "Engineering the creative co-design of augmented digital experiences with cultural heritage," in IS-EUD 2015: End-User Development, 2015, pp. 42-57.

[11] F. Cardinali and DigiCULT. (2003) Learning objects from cultural and scientific heritage resources. [DigiCULT]. [Online]. Available: https://bit.ly/3bVBQjv

[12] R. Mendoza, D. Vargas, S. Baldiris, and R. Fabregat, "Social Heritage: Augmented reality application to heritage education," in AVR 2015: Augmented and Virtual Reality, 2015, pp. 17-24.

[13] J. M. Keller, IMMS: Instructional materials motivation survey. Tallahassee, FL: Florida State University, 1987.

[14] Institute of Electrical and Electronics Engineers (IEEE), "IEEE Standard for Learning Technology - Learning Technology Systems Architecture (LTSA)," in IEEE std 1484.1-2003, 2003, pp. 1-97.

[15] Institute of Electrical and Electronics Engineers (IEEE), “Learning Technology Standards Committee (IEEE LTSC) Annual Status Report 2017," in IEEE LTSC, 2017.

[16] J. M. Keller, Motivational Design for Learning and Performance. The ARCS model approach, 1st ed. New York, USA: Springer US, 2010.

[17] J. M. Keller, "Development and use of the arcs model of instructional design," Journal of Instructional Development, vol. 10, no. 3, pp. 2-10, 1987.

[18] J. L. Bacca, "Framework for the design and development of motivational augmented reality learning experiences in vocational education and training," Ph. D. dissertation, Departament d'Arquitectura i Tecnologia de Computadors, Universitat de Girona, Girona, Spain, 2017.

[19] T. H. Chiang, S. J. Yang, and G. Hwang, "An Augmented Reality-based mobile learning system to improve Students' learning achievements and motivations in natural science inquiry activities," Educational Technology \& Society, vol. 17, no. 4, pp. 352-365, Oct. 2014.

[20] K. Chin, K. Lee, and Y. Chen, "Impact on student motivation by using a QR-Based ULearning material production system to create authentic learning experiences," IEEE Transactions on Learning Technologies, vol. 8, no. 4, Oct 2015. [Online]. Available: https://doi.org/10.1109/TLT.2015.2416717

[21] C. Chen, Y. Chou, and C. Huang, "An augmented-reality-based concept map to support mobile learning for science," The Asia-Pacific Education Researcher, vol. 25, no. 4, pp. 567--578, Feb. 2016.

[22] S. L. Lohr, Ed., Multiple frame surveys, ser. Handbook of Statistics. Elsevier Science Ltd, 2019, pp. 71-88.

[23] R. Small, "Motivation in instructional design," ERIC Clearinghouse on Information and Technology, vol. 27, no. 5, pp. 1-5, Jul. 1997. 